\title{
Capacity Evaluation of ISKON Intersection on S.G Highway in Ahmedabad-A Case Study
}

\author{
Alpana Jha \\ Lecturer (Civil Engineering), Government Polytechnic, Ahmedabad, Gujarat
}

\begin{abstract}
Space sharing intersection e.g rotaries and pretimed signals are widely used to control the intersections. Space sharing intersection are intended to give equal priority and permit continuous movement of all intersecting vehicle flows. For higher traffic volumes, space sharing intersections such as rotary is not preferable due to increase in congestion and overall intersection delay and conflicts. In pretimed signal, green times for the phases remain constant for the particular period of the day, although demand fluctuates during that period. This problem can be eliminated by providing over bridge at rotary intersection. This study presents literature review on Rotary Intersection and capacity and level of serviceon and literature on case study. ISKON Cross Road on S.G Highway in Ahmedabad was selected as a case study intersection. The flow rate, saturation flow rate and its adjustment factors, capacity, volume to capacity ratio, delay for lane group, approaches and intersection as whole and delay comparison with level of service were calculated as described in highway Capacity Manual 2000. Study proves that ISKON Cross Road at-grade intersection was required to be converted to grade separated intersection to reduce congestion and delay.
\end{abstract}

Keywords: Rotary intersection, Capacity, Level of service, delay, Critical v/c ratio

\section{Introduction}

Rotary intersections or roundabouts are special form of atgrade intersections laid out for the movement of traffic in one direction around a central traffic island. Essentially all the major conflicts at an intersection namely the collision between through and right-turn movements are converted into milder conflicts namely merging diverging. The vehicles entering the rotary are gently forced to move in a clockwise direction in orderly fashion. They then weave out of the rotary to the desired direction.

\section{Advantages and Disadvantages of Rotary}

The key advantages of a rotary intersection are listed below:

1) Traffic flow is regulated to only one direction of movement, thus eliminating severe conflicts between crossing movements.

2) All the vehicles entering the rotary are gently forced to reduce the speed and continue to move at slower speed. Thus, none of the vehicles need to be stopped, unlike in a signalized intersection.

3) Because of lower speed of negotiation and elimination of severe conflicts, accidents and their severity are much less in rotaries.

4) Rotaries are self governing and do not need practically any control by police or traffic signals.

5) They are ideally suited for moderate traffic, especially with irregular geometry, or. intersections with more than three or four approaches

Although rotaries offer some distinct advantages, there are few specific limitations for rotaries which are listed below.

1) All the vehicles are forced to slow down and negotiate the intersection. Therefore, the cumulative delay will be much higher than channelized intersection.

2) Even when there is relatively low traffic, the vehicles are forced to reduce their speed.

3) Rotaries require large area of relatively flat land making them costly at urban areas.
4) The vehicles do not usually stop at a rotary. They accelerate and exit the rotary at relatively high speed. Therefore, they are not suitable when there is high pedestrian movements.

\section{Guidelines For The Selection Of Rotaries}

Because of the above limitation, rotaries are not suitable for every location. There are few guidelines that help in deciding the suitability of a rotary. They are listed below.

1) Rotaries are suitable when the traffic entering from all the four approaches are relatively equal.

2) A total volume of about 3000 vehicles per hour can be considered as the upper limiting case and a volume of 500 vehicles per hour is the lower limit.

3) A rotary is very beneficial when the proportion of the right-turn traffic is very high; typically if it is more than 30 percent.

4) Rotaries are suitable when there are more than four approaches or if there is no separate lanes available for right-turn traffic. Rotaries are ideally suited if the intersection geometry is complex. As noted earlier, the traffic operations at a rotary are three; diverging, merging and weaving. All the other conflicts are converted into these three less severe conflicts.

a) Diverging: It is a traffic operation when the vehicles moving in one direction is separated into different streams according to their destinations.

b) Merging: Merging is the opposite of diverging. Merging is referred to as the process of joining the traffic coming from different approaches and going to a common destination into a single stream.

c) Weaving: Weaving is the combined movement of both merging and diverging movements in the same direction. 


\section{International Journal of Science and Research (IJSR) \\ ISSN (Online): 2319-7064}

Index Copernicus Value (2013): 6.14 | Impact Factor (2014): 5.611

These movements are shown in figure 1

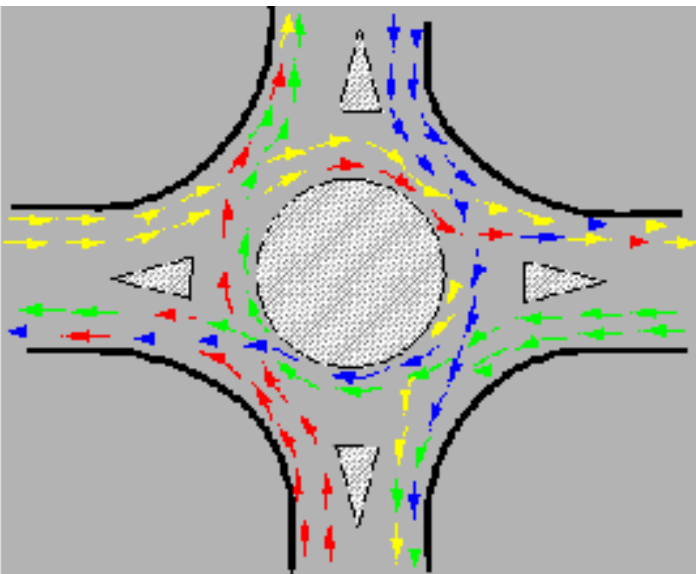

Figure 1: Traffic operations in a rotary

\section{Capacity and Level-of-Service Concepts}

The HCM 2000 presents methods for analyzing capacity and level of service for a broad transportation facilities. It provides procedures for analyzing streets and highways, bus and on-street light rail transit, and pedestrians and bicycle paths.

Facilities are classified into two categories of flow: uninterrupted and interrupted. Uninterrupted-flow- facilities have no fixed elements, such as traffic signals. Traffic flow conditions result from the interactions among vehicles in the traffic stream and between vehicles and geometric and environmental characteristics of the roadway. Interrupted-flow facilities have controlled and uncontrolled access points that can interrupted the traffic flow. These access points including traffic signals, stop signs, yield signs, and of control that stop traffic periodically (or slow it significantly), irrespective of amount of traffic.

Uninterrupted and interrupted flows describe the type of facilities, not the quality the traffic flow at any given time. A freeway experiencing extreme congestion, for example, is still an Uninterrupted- flow facility because the causes of congestion are internal.

The analysis of interrupted-flow facilities must account for the impact of fixed interruptions. A traffic signal, for example, limits the time available to various movements in an intersection. Capacity is limited not only by the physical space but by the time available for movements. Transit, pedestrian, and bicycle flows generally are considered to be interrupted, Uninterrupted flow might be possible under certain circumstances, such as in a long bus way without stops or along a pedestrian corridor. However, in most situations, capacity is limited by stops along the facility.

\section{Case Study- ISKON Intersection}

ISKON Intersection was a rotary intersection with following geometric details:
Table 1: Geometric details for Case study Intersection

\begin{tabular}{|c|c|c|c|c|c|}
\hline \multicolumn{6}{|c|}{ Name of intersection: ISKON Intersection } \\
\hline Approach & \begin{tabular}{c|} 
Lane \\
Group
\end{tabular} & $\begin{array}{l}\text { No. of lanes } \\
\text { Per lane } \\
\text { Group }\end{array}$ & $\begin{array}{l}\text { Width } \\
\text { per lane } \\
(\mathrm{m})\end{array}$ & $\begin{array}{l}\text { Approach } \\
\text { Width } \\
\text { (m) }\end{array}$ & $\begin{array}{c}\text { Approach } \\
\text { Grade } \\
(\%)\end{array}$ \\
\hline \multirow{3}{*}{ North } & Left turn & 1 & 3 & \multirow{3}{*}{28} & \multirow{3}{*}{0} \\
\hline & Through & 2 & 3 & & \\
\hline & Right turn & 1 & 3 & & \\
\hline \multirow{3}{*}{ South } & Left turn & 1 & 3 & \multirow{3}{*}{28} & \multirow{3}{*}{0} \\
\hline & Through & 2 & 3 & & \\
\hline & Right turn & 1 & 3 & & \\
\hline \multirow{3}{*}{ East } & Left turn & 1 & 3 & \multirow{3}{*}{26} & \multirow{3}{*}{0} \\
\hline & Through & 2 & 3 & & \\
\hline & Right turn & 1 & 3 & & \\
\hline \multirow{3}{*}{ West } & Left turn & 1 & 2.5 & \multirow{3}{*}{18} & \multirow{3}{*}{0} \\
\hline & Through & 1 & 2.5 & & \\
\hline & Right turn & 1 & 2.5 & & \\
\hline
\end{tabular}

Approach width $=$ one direction lane group width + median width + another direction flow lane group width Approach width (North) $=12+4+12=28$

Approach width (South) $=12+4+12=28$

Approach width (East) $=12+2+12=26$

Approach width $($ West $)=7.5+3+7.5=18$

\section{Comparison between Capacity and Present Traffic} Volume

Table 2 shows the comparison between capacity and present traffic volume of ISKON intersection. It indicates that ISKON intersection capacity is $3138 \mathrm{veh} / \mathrm{h}$ while the present traffic volume at ISKON intersection is $6107 \mathrm{veh} / \mathrm{h}$. It means the present traffic is $94 \%$ more than capacity of ISKON intersection.

Table 2: Comparison Between Capacity And Present Traffic Volume

\begin{tabular}{|c|c|c|}
\hline Approach & $\begin{array}{c}\text { Capacity } \\
\text { veh/h }\end{array}$ & $\begin{array}{c}\text { Present Traffic Volume } \\
\text { veh/h }\end{array}$ \\
\hline North & 873 & 1770 \\
\hline South & 753 & 1423 \\
\hline East & 900 & 1495 \\
\hline West & 612 & 1419 \\
\hline $\begin{array}{c}\text { Intersection } \\
\text { Total }\end{array}$ & 3138 & 6107 \\
\hline
\end{tabular}

(source: Traffic Survey)

\section{Comparison between Volume to Capacity Ratio and Flow Condition for Lane Groups}

There are three different conditions for measuring flow condition These are:

1) When $v / c$ ratio less than one, flow condition is under saturated

2) When v/c ratio equal to one, flow condition is saturated

3) When v/c ratio more than one, flow condition is over saturated

Table 3 shows the comparison between $\mathrm{v} / \mathrm{c}$ ratio and flow condition for lane groups. It indicates that in all approach left turn lane group flow condition is under saturated, because it carried. Continuous traffic movement. Remaining lane group for all approach flow condition is over saturated. 


\section{International Journal of Science and Research (IJSR) \\ ISSN (Online): 2319-7064 \\ Index Copernicus Value (2013): 6.14 | Impact Factor (2014): 5.611}

Table 3: Comparison Between v/c Ratio And Flow Condition for Lane Groups

\begin{tabular}{|c|c|c|c|c|}
\hline S.No & Approach & Lane Group & v/c Ratio & Flow condition \\
\hline 1 & \multirow{3}{*}{ North } & Left turn & 0.60 & Under saturated flow \\
\hline 2 & & Through & 3.8 & Over saturated flow \\
\hline 3 & & Right turn & 1.68 & Over saturated flow \\
\hline 4 & \multirow{3}{*}{ South } & Left turn & 0.56 & Under saturated flow \\
\hline 5 & & Through & 3.96 & Over saturated flow \\
\hline 6 & & Right turn & 1.14 & Over saturated flow \\
\hline 7 & \multirow{3}{*}{ East } & Left turn & 0.61 & Under saturated flow \\
\hline 8 & & Through & 3.05 & Over saturated flow \\
\hline 9 & & Right turn & 1.32 & Over saturated flow \\
\hline 10 & \multirow{3}{*}{ West } & Left turn & 0.71 & Under saturated flow \\
\hline 11 & & Through & 4.85 & Over saturated flow \\
\hline 12 & & Right turn & 1.39 & Over saturated flow \\
\hline
\end{tabular}

Comparison between Critical Volume to Capacity Ratio for Intersection and Flow Condition

There are three different conditions for measuring critical flow condition. These are

1) When critical $v / c$ ratio for intersection less than one, flow condition is under saturated

2) When critical $v / c$ ratio for intersection equal to one, flow condition is saturated

3) When critical $\mathrm{v} / \mathrm{c}$ ratio for intersection more than one, flow condition is over saturated

There are four lane groups which behave as a critical lane group. They are:

1. North approach through lane group

2. South approach through lane group

3. East approach through lane group

4. West approach through lane group

Table 4 shows the comparison between critical $\mathrm{v} / \mathrm{c}$ ratio for intersection and flow condition. It indicates critical $\mathrm{v} / \mathrm{c}$ ratio for ISKON intersection is 4.85 which is more than one - So, flow condition for ISKON intersection is over saturated.

Table 4: Comparison between critical v/c Ratio for Intersection and Flow Condition

\begin{tabular}{|c|c|c|c|c|}
\hline S. No & Approach & $\begin{array}{c}\text { Lane } \\
\text { Group }\end{array}$ & $\begin{array}{c}\text { Critical v/c Ratio } \\
\text { for Intersection }\end{array}$ & $\begin{array}{c}\text { Intersection } \\
\text { Flow Condition }\end{array}$ \\
\hline 1 & North & Through & 3.8 & \multirow{2}{*}{ Over saturated } \\
\hline 2 & South & Through & 3.96 & Flow \\
\hline 3 & East & Through & 3.05 & \\
\hline 4 & West & Through & 4.85 & \\
\hline
\end{tabular}

Comparison between Delay and Level of Service

Table 5: Comparison between Delay And Level Of Service

\begin{tabular}{|c|c|c|c|c|}
\hline S. No. & Approach & Lane Group & $\begin{array}{l}\text { Lane Group } \\
\text { Delay s/veh }\end{array}$ & $\begin{array}{c}\text { Lane Group } \\
\text { Level of Service }\end{array}$ \\
\hline 1 & \multirow{3}{*}{ North } & Left turn & 29 & $\mathrm{C}$ \\
\hline 2 & & Through & 86.9 & $\mathrm{~F}$ \\
\hline 3 & & Right turn & 86.9 & $\mathrm{~F}$ \\
\hline 4 & \multirow{3}{*}{ South } & Left turn & 35 & $\mathrm{D}$ \\
\hline 5 & & Through & 94.6 & $\mathrm{~F}$ \\
\hline 6 & & Right turn & 94.6 & $\mathrm{~F}$ \\
\hline 7 & \multirow{3}{*}{ East } & Left turn & 23.2 & $\mathrm{C}$ \\
\hline 8 & & Through & 85.4 & $\mathrm{~F}$ \\
\hline 9 & & Right turn & 85.4 & $\mathrm{~F}$ \\
\hline 10 & \multirow{3}{*}{ West } & Left turn & 33 & $\mathrm{D}$ \\
\hline 11 & & Through & 106.5 & $\mathrm{~F}$ \\
\hline 12 & & Right turn & 106.5 & $\mathrm{~F}$ \\
\hline
\end{tabular}

Comparison between Delay and LOS for Approach And Intersection

\begin{tabular}{|c|c|c|c|c|}
\hline Approach & $\begin{array}{c}\text { Approach } \\
\text { Delay }\end{array}$ & $\begin{array}{c}\text { Approach } \\
\text { LOS }\end{array}$ & $\begin{array}{c}\text { Intersection } \\
\text { Delay }\end{array}$ & $\begin{array}{c}\text { Intersection } \\
\text { LOS }\end{array}$ \\
\hline North & 67.7 & F & 72.3 & F \\
\cline { 1 - 3 } South & 74.73 & F & & \\
\cline { 1 - 3 } East & 64.66 & F & & \\
\hline West & 82.1 & F & & \\
\hline
\end{tabular}

\section{Conclusion}

The capacity of ISKON intersection is less than present traffic demand as described in section 2. So it may be needed to improve present signalized condition or present geometric condition. Here v/c ratio for through and right turn traffic movements for all approach of ISKON intersection are over saturated. It indicates of actual or potential breakdown. Critical v/c ratio at ISKON intersection is greater than one. This indicates that the signal and geometric design cannot accommodate the combination of critical flows at the intersection. This condition may be ameliorated by increased cycle length, changes in the phasing plan, and basic changes in geometrics. Further, here all left turns and right turns are protected phases and $\mathrm{v} / \mathrm{c}$ ratios are unacceptable, it is probable that geometric changes will be required to ameliorate the condition. Also there are comparison between delay and level of service . It indicates that ISKON intersection approach delay and intersection delay is very high and it place in LOS F.

\section{References}

[1] Saxena C, A Course in Traffic Planning and Design Second Edition, Dhanpat Rai Publication.

[2] Kadiyali L.R., Traffic Engineering and Transport Planning sixth reprint 2004, Khanna Publishers.

[3] Khanna S. K., Justo C.E.G., Highway engineering Eighth edition, New Chand and Bros, Roorkee.

[4] Highway Capacity Manual 2000 by Transportation Research Board, National Research council, Washington D.C

[5] Dissertation on " Capacity analysis of signalized Intersection in Devloping Countries" 2002 by Gopal R. Patil. 